\title{
Social Cognitive Domain Coordination in Left- Behind Children: A Comparative Study of Left- Behind and Non-Left-Behind Children in Rural China
}

\author{
Jianjin Liu \\ (Guangdong University of Foreign Studies, liujianjinljj@126.com)
}

\section{Introduction}

The combined forces of China's open-door economic reform, the ensuing relaxation of migration restrictions by the Chinese government, and the sweeping trend of globalization have led to an unprecedented growth of economically driven rural-to-urban migration in China. This has been called the largest migration in human history (Zhang 2004). The migrants contribute much to urban development. However, because of the household registration system (hukouzhidu) which separates the rural and urban areas and their own constrains in economy, they are not involved in the urban security system and cannot become permanent workers in cities. In other words, the migrants can only work in cities; they cannot afford support for the whole family. Migrant workers have to leave some family members behind in the countryside, mainly women, children, and the old. Left-behind children in rural China refer to those children whose parent or parents migrate from the countryside to other more developed areas. The left-behinds have been left in rural hometowns and cannot live with their parents (All-China Women's Federation 2013). According to China's sixth census data in 2010, the number of left-behind children has soared to 61.02 million, accounting for $37.7 \%$ of rural children and $21.88 \%$ of all children in China. Most of these children (32.67\% of left-behinds) live with their grandparents.

Wen and Lin (2012) examined psychological, behavioural, and educational outcomes and the psychosocial contexts of these outcomes among left-behind children compared to those living in non-migrant families. The results showed that left-behind children were disadvantaged in health behaviour and school engagement but not in perceived satisfaction. Ming, Su and $\mathrm{Li}$, etc. (2014) found that little difference in the Positive Youth Development (PYD) outcomes was detected by parental migration status. On other outcomes (i.e., self-rated health, school grades, educational aspirations, problem behaviour), positive influences of parental migration were observed. $\mathrm{Su}, \mathrm{Li}$, and Lin (2013) found there were no significant differences in school satisfaction and happiness among left-behind and non-left-behind children. 
Loneliness was the most common and important experience of left-behind children. Parent-child communication is important for the development of all rural children. So we can see from those studies that the influences of parent migration are controversial; both negative and positive influences were found.

Although the outcomes of the differences of education, health, behaviour, satisfaction between left-behind and non-left behind child are controversial, the moral reasoning and moral character between the two groups are one-sided. Wang and Li (2014) believe that it's very hard for leftbehind children to receive proper education due to the absence of parents and the aging and illiteracy of grandparents. Meanwhile, the left-behind children may be more perplexed by the conflicts and complexity brought by the huge transition of the society. So it is more difficult for them to develop moral concepts and moral reasoning, which further influence their moral character and identity. Du (2012) regards left-behind children as more selfish, wilful, and disrespectful due to the lack of parents' care and grandparents' pampering. However, most of these studies have no empirical evidence, and the conclusions are mainly based on researchers' deduction and contemplation.

Meanwhile, the issue of left-behind children has become one of the sensations in social media in China recently. For example, in November, 2015, in Hunan Province, one of the main provinces for migrants, three students killed their primary female teacher when they were detected stealing in the shop in the primary school. Such issues left an image of left-behind children as indifferent, even cruel, and they are considered a high-risk population for delinquency and crimes. Are left-behind children really very different from non-left-behind children? What's the real image of left-behind children? As researchers, we should not follow the steps of social media and magnify the phenomenon. The purpose of this paper is to explore the moral development of left-behind children (LBs) and non-left-behind children (NLs), based on social cognitive domain theory, to see whether there are some differences between them.

\section{Social Cognitive Domain Theory}

Social cognitive domain theory (also called domain theory) is the newly developed theoretical branch of cognitive developmental psychology which began in the 1980s. Over 40 years of study and research in domain theory proves that people have different perceptions and judgments about issues in different social domains. They differentiate between moral, conventional, and personal domains from a very young age (Smetana \& Braeges 1990). Moral domain refers to prescriptive judgments of justice, rights, and welfare pertaining to how people ought to relate to each other. Moral prescriptions are not related to the social context, nor are they defined by it. Social conventions are behavioural uniformities that serve to coordinate social interactions and 
are tied to the contexts of specific social systems. Conventions are based on arbitrary actions that are relative to social contexts (Turiel 1983). Personal issues comprise the set of social actions whose importance and effects are perceived to be primarily upon the actor rather than other individuals or the societal structure, for example, choosing one's own friends or one's own hair style (Nucci 1981).

Various methodologies have been utilized to assess children and adolescents' evaluations of moral, conventional, and personal rules (Turiel 1983). One important measure is the utilization of criterion judgments, in which individuals are presented with a set of questions in order to identify and classify the parameters that define a certain domain (i.e., moral, conventional, and personal). The results of research using this method over the last 40 years have supported that children and adolescents have similar judgments on these issues (Smetana 2006; Tisak et al. 2006; Turiel 2006). More specifically, children and adolescents consider moral violations to be wrong no matter if there is a formal rule on it (rule contingency) or an authority permitting it (authority contingency) or not. They also consider moral rules to be unalterable (alterability) and generalizable (generalizability) across different situations. In contrast, children and adolescents consider conventional rules to be arbitrary and variable in different contexts. Conventional violations are considered wrong only when there is a formal rule about them. With regard to personal domain infractions, children perceive these behaviours to be matters of individual prerogatives. This body of research has demonstrated that children consider moral rules to be more inviolate and more important than conventional rules and conventional rules to be more inviolate and more important than personal rules.

Children and adolescents also are asked to justify their reasoning on moral, conventional, and personal issues - i.e., to offer reasons to support their evaluations. In response to questions about moral transgressions, children mainly provide justifications concerning individual rights, fairness and justice. However, in response to questions about violations of convention, children's justifications pertain to rules, punishments, and authority. As for reasoning in support of evaluations of personal rules, children focus on the individual's own preferences and choices.

Except for exploring judgments and justifications among normal populations, theorists in domain theory also have tried to look into population growing up in abnormal environments. Nucci (1982) assessed school-aged children categorized as normally behaved children with those labelled as behaviourally disordered (BD). Both groups of children rated moral transgressions as most wrong, followed by conventional and personal transgressions. However, the BD children were less likely to consider moral transgression to be wrong when there were no explicit rules than normally behaved children did. Also, BD children were less likely to view personal acts as 
within their own jurisdiction than did normal children. There were also group differences in the children's justifications for their evaluations of wrongness. When considering moral violations, BD children focused more on the violation of rules and the subsequent punishment that could follow, whereas the normally behaved children were mainly concerned with the welfare of the victim. David Mullins \& Marie S. Tisak (2006) studied the evaluations of moral, conventional, and personal rules and violations of foster youth and found that foster youth, like normal youth, could differentiate between the three domains but that they used more conventional justifications compared with normal youth when they offered reasons to support their evaluations. Particularly, they justified moral and personal issues with conventional reasons.

The findings described in these previous studies support the premise that children and adolescents that grow up in nonnormative environments may not evaluate the events in the same manner as members of normative populations. The LB grow up in the circumstances without the companionship and instructions of their parent(s), and this may distort their perceptions of moral, conventional, and personal rules and justify the violations to these rules in different ways.

\section{The Current Study}

The current study uses criterion judgment methodology (Turiel 1983) to compare the evaluations and judgments of social rules in moral, conventional and personal domains between left-behind children (LBs) and non-left-behind children (NLs) in rural China to see whether there are some differences between the two groups. It was predicted that both LBs and NLs would make distinctions in evaluating actions and violations of moral, conventional, and personal domains. Meanwhile, they would regard moral transgressions as the most wrong, followed by conventional and personal rule violations. Previous researches supported that non-normative samples - i.e., behaviourally disordered children (Nucci \& Herman, 1982) , juvenile delinquents (Tisak \& Jankowski 1996) and foster youth (Mullins \& Tisak 2006)-were found to offer conventional justifications in response to infractions in all domains, especially in moral infractions. So we expected that LBs would use more rationales compared with NLs to support their judgments across the domains by referring to conventional justifications, including rules, punishment, and authority.

With regard to age differences, it was expected that younger participants, in contrast to older ones, would treat personal rule violations as conventions. This was predicted because previous research indicates that with increasing age, children become more likely to put personal issues under their own jurisdiction and not under the jurisdiction of parents and authorities (Smetana, 1988). Although past research (e.g. Tisak 1986; Tisak\&Turiel 1984) 
has found no significant sex differences in domain reasoning, we assessed differences between boys and girls in the present study because evaluating social domains has not been investigated in left-behind children.

\section{Methods}

\subsection{Participants}

Two cohorts ( $M=10.6, S D=.90 ; M=13.7, S D=.62)$ of 47 (22 male, 27 female) LBs were interviewed. Their parents have been away from home for more than five years, and they lived with their grandparents. Two cohorts $(M=11.2, S D=.56$; $\mathrm{M}=13.3, \mathrm{SD}=.50$ ) of 40 (half male-half female) NLs were also included in the interview.

\subsection{Measurement and Procedure}

All participants were interviewed with a semi structural outline (Smetana 2006; Tisak et al 2006; Turiel 2006). All interviews took place in an independent room in the local school and lasted for about 30 minutes. The interviews consisted of vignettes in moral, conventional, and personal domains accompanied by a set of questions concerning each vignette.

\subsection{Vignettes}

There was a total of eight vignettes, two for each of four different domain types of rule. Two sets of rules pertained to the moral domain: 1. physical consequences (e.g. hitting), 2. psychological consequences (e.g. laughing at others). The third type of rules concerned reasoning in the conventional domain and focused on smooth functioning of social organization (e.g. wearing school uniform, calling the teacher's by first name). The fourth type assessed reasoning in the personal domain and concerns about personal preferences and choices (e.g. hair style, allowance). The scenarios presented in the events were derived from the previous researches (Smetana et al. 1984; Tisak \& Turiel 1984; Tisak \& Turiel 1988; Nucci 1981). The vignettes were read aloud to the participants in a random order.

\section{Criteria Judgment and Coding}

A set of questions were asked after each scenario described below so that each type of rules would be posed twice with two vignettes in each domain.

Act evaluation concerned whether the act is right (acceptable) or wrong (unacceptable) (e.g. Is it right or wrong to hit others?). Responses were coded as follows: $1=y e s$, indicating it would be right to hit others; $2=$ maybe; and $3=$ no, indicating it would be wrong to hit others.

Legitimacy of rulemaking by authority pertained to the acceptability for the authority to make rules on certain acts (e.g. Is it acceptable or not acceptable 
for parents to make a rule that you cannot hit?). Reponses were coded as follows: $1=y e s$, indicating it would be acceptable to make the rule; $2=$ maybe; $3=$ no, indicating it would be unacceptable to make the rule.

Alterability concerned whether it is right (acceptable) or wrong (not acceptable) to abolish or negate a rule about the act (e.g. Would it be acceptable or unacceptable if parents no longer had a rule on hitting?). Responses were coded as: $1=y e s$, indicating it would be acceptable to abolish the rule; $2=$ maybe; $3=$ no, indicating it would be unacceptable to get rid of the rule.

Rule contingency pertained to whether the behaviour is right (acceptable) or wrong (unacceptable) if there were no rule on the act (e.g. Would it be acceptable to hit others if there were no rule prohibiting hitting?). Responses were: 1=yes, indicating it would be right (acceptable) to hit; $2=$ maybe; $3=$ no, indicating it would be wrong (unacceptable) to hit.

Generalizability concerned whether it is right (acceptable) or wrong (unacceptable) if the rule only exists in some contexts but not all contexts (e.g. Would it be acceptable or not acceptable if some parents allowing hitting?). Responses were coded as: $1=y e s$, indicating it would be acceptable to allow hitting; $2=$ maybe; $3=$ no, indicating it would be not acceptable to allow hitting.

The responses for each question were summed to get a score ranging from 2-6 for each participant. A score of "2" means a strong affirmative attitude and "6" means a strong negative response (not acceptable).

\section{Justifications and Coding}

To explore the reasoning behind the judgments, participants were asked to offer reasons for their judgments. According to previous researches (Smetana 2006; Tisak et al. 2006; Turiel 2006) and the situation in China, justifications are grouped into seven categories: 1. moral concerns about individual's rights and welfare, including physical welfare and psychological welfare; 2 . conventional pertains to customs and social norms that help facilitate the organization and smooth functioning of social situations and institutes; 3. punishment concerns the actual consequences ensuing from the infraction or transgression of a rule or possibilities of punishment; 4. personal growth pertains to behaviours that enhance developmental outcomes (e.g. They will understand this later); 5 . retaliation concerns negative behaviours as a result of others' actions (e.g. If he hits you first, then you can hit back); 6) personal choice pertains to individuals' preferences and choices (e.g. A person should be able to choose what he wants to wear); and 7. interpersonal relationship concerns the harm the infraction may bring to interpersonal relationships (e.g. That will hurt their friendship).

A binomial classification system was used to code justifications. A "1" was scored each time when a participant used a justification consistent with the category and a " 0 " was scored for each justification category that the 
participant did not use. Two independent judges coded $30 \%$ of the justification data and the obtained interrater reliability based on Cohen's kappa was $85 \%$. Disagreements were discussed and agreed upon by both of the raters.

\section{Results}

\subsection{Criteria judgments}

Responses were analyzed using mixed design analyses of variance (ANOVAs). The moral domain was subdivided into physical and psychological transgressions resulting in four types of domain transgression events: moral physical, moral psychological, conventional, and personal. Each of these was then analyzed for two effects: age (younger or older), gender (male or female), and status (LB or NL) - a $4 \times 2 \times 2 \times 2$ mixed ANOVA. The means and standard deviations of criterion judgment are shown in Table 1 .

\begin{tabular}{|c|c|c|c|c|c|c|}
\hline \multirow[t]{2}{*}{ Criteria } & \multicolumn{3}{|c|}{ Moral } & \multirow{2}{*}{ Conventional } & \multirow{2}{*}{ Personal } & \multirow{2}{*}{$\begin{array}{l}\text { ANOVA } \\
\text { results }\end{array}$} \\
\hline & & hysical & Psychological & & & \\
\hline \multirow{2}{*}{ Act evaluation } & $L^{a}$ & $5.97(.263)$ & 5.97(.184) & $5.79(.522)$ & $4.00(1.250)$ & $A^{b}$ \\
\hline & NL & $6.00(.000)$ & $6.00(.000)$ & $5.87(.469)$ & $4.08(1.439)$ & $A, B C^{c}$ \\
\hline \multirow{2}{*}{ Legitimacy } & LB & $2.21(.720)$ & $2.09(.339)$ & $2.44(.887)$ & $3.58(1.212)$ & $A, A B$ \\
\hline & NL & $2.10(.378)$ & $2.58(.958)$ & $2.58(.958)$ & $3.65(1.291)$ & $A$ \\
\hline \multirow{2}{*}{ Alterability } & LB & $5.95(.297)$ & $5.67(.906)$ & $3.68(.1 .114)$ & $3.28(1.364)$ & $A, A B$ \\
\hline & NL & $5.95(.316)$ & $3.63(.897)$ & $3.63(.897)$ & $2.82(1.227)$ & $A, A B$ \\
\hline Rule & LB & $5.96(.265)$ & $5.80(.699)$ & $3.71(.918)$ & $3.41(1.332)$ & $A, B$ \\
\hline contingency & NL & $5.95(.316)$ & $3.50(.877)$ & $3.50(.877)$ & $2.77(1.012)$ & $A, A B C$ \\
\hline Generali- & LB & $5.83(.775)$ & $5.67(.893)$ & $3.84(.970)$ & $3.46(1.307)$ & $A, B C$ \\
\hline zability & NL & 5.93.(349) & $3.90(.900)$ & $3.90(.900)$ & $3.38(1.349)$ & $A$ \\
\hline
\end{tabular}

\section{Table 1. Mean (and SD) Criterion Judgment Scores}

Act evaluation. Children's judgments about whether certain behavior is right or not right varied by social domains, $F(1.3,102.8)=159.7^{1}, p<.01, \eta_{p}{ }^{2}=.67$. The mean (and $S D$ ) acceptability scores are presented in Table 2 for each domain and by participants' status and age. Pairwise comparison showed that

\footnotetext{
${ }^{1}$ Mauchley's test for sphericity was performed to assess and reduce positive bias. In situations in which sphericity was lacking the Greenhouse-Geisser result is reported.
} 



\begin{tabular}{|c|c|c|c|c|c|c|c|c|c|c|c|c|c|c|c|c|c|}
\hline \multirow[t]{3}{*}{ Criteria } & \multicolumn{8}{|c|}{ Moral } & \multirow{2}{*}{\multicolumn{4}{|c|}{ Conventional }} & \multirow{2}{*}{\multicolumn{4}{|c|}{ Personal }} & \multirow{3}{*}{$\begin{array}{l}\text { ANOVA } \\
\text { Results }\end{array}$} \\
\hline & \multicolumn{4}{|c|}{ Physical } & \multicolumn{4}{|c|}{ Psychological } & & & & & & & & & \\
\hline & YL & YN & OL & $\mathrm{ON}$ & YL & YN & OL & $\mathrm{ON}$ & YL & YN & OL & $\mathrm{ON}$ & YL & YN & OL & $\mathrm{ON}$ & \\
\hline Act evaluation & $\begin{array}{c}5.9 \\
(.42)\end{array}$ & $\begin{array}{c}6.0 \\
(.00)\end{array}$ & $\begin{array}{c}6.0 \\
(.00)\end{array}$ & $\begin{array}{c}6.0 \\
(.00)\end{array}$ & $\begin{array}{c}5.9 \\
(.29)\end{array}$ & $\begin{array}{c}6.0 \\
(.00)\end{array}$ & $\begin{array}{c}6.0 \\
(.00)\end{array}$ & $\begin{array}{c}6.0 \\
(.00)\end{array}$ & $\begin{array}{c}5.8 \\
(.50)\end{array}$ & $\begin{array}{c}5.9 \\
(.46)\end{array}$ & $\begin{array}{c}5.8 \\
(.52)\end{array}$ & $\begin{array}{c}5.9 \\
(.49)\end{array}$ & $\begin{array}{c}4.1 \\
(1.31)\end{array}$ & $\begin{array}{c}3.9 \\
(1.67)\end{array}$ & $\begin{array}{c}3.8 \\
(1.25)\end{array}$ & $\begin{array}{c}4.2 \\
(1.19)\end{array}$ & $\begin{array}{c}A, B C \\
A B C\end{array}$ \\
\hline Legitimacy & $\begin{array}{c}2.5 \\
(1.07)\end{array}$ & $\begin{array}{c}2.1 \\
(.45)\end{array}$ & $\begin{array}{c}2.1 \\
(.40)\end{array}$ & $\begin{array}{c}2.1 \\
(.31)\end{array}$ & $\begin{array}{c}2.1 \\
(.29)\end{array}$ & $\begin{array}{c}2.1 \\
(.22)\end{array}$ & $\begin{array}{c}2.1 \\
(.44)\end{array}$ & $\begin{array}{c}2.1 \\
(.31)\end{array}$ & $\begin{array}{c}2.6 \\
(1.09)\end{array}$ & $\begin{array}{c}2.9 \\
(1.38)\end{array}$ & $\begin{array}{c}2.3 \\
(.68)\end{array}$ & $\begin{array}{c}2.3 \\
(.66)\end{array}$ & $\begin{array}{c}3.3 \\
(1.42)\end{array}$ & $\begin{array}{c}3.7 \\
(1.49)\end{array}$ & $\begin{array}{c}3.9 \\
(.98)\end{array}$ & $\begin{array}{c}3.6 \\
(1.09)\end{array}$ & $A, B, A B$ \\
\hline Alterability & $\begin{array}{c}6.0 \\
(.00)\end{array}$ & $\begin{array}{c}6.0 \\
(.00)\end{array}$ & $\begin{array}{c}5.9 \\
(.45)\end{array}$ & $\begin{array}{c}5.9 \\
(.48)\end{array}$ & $\begin{array}{c}5.3 \\
(1.28)\end{array}$ & $\begin{array}{c}5.9 \\
(.48)\end{array}$ & $\begin{array}{c}5.9 \\
(.40)\end{array}$ & $\begin{array}{c}5.8 \\
(.55)\end{array}$ & $\begin{array}{c}3.9 \\
(1.27)\end{array}$ & $\begin{array}{c}3.7 \\
(.98)\end{array}$ & $\begin{array}{c}3.7 \\
(.76)\end{array}$ & $\begin{array}{c}3.6 \\
(.83)\end{array}$ & $\begin{array}{c}3.1 \\
(1.36)\end{array}$ & $\begin{array}{c}2.5 \\
(.96)\end{array}$ & $\begin{array}{c}3.3 \\
(1.40)\end{array}$ & $\begin{array}{c}3.1 \\
(1.02)\end{array}$ & $A, A B$ \\
\hline $\begin{array}{l}\text { Rule } \\
\text { contingency }\end{array}$ & $\begin{array}{c}6.0 \\
(.00)\end{array}$ & $\begin{array}{c}5.9 \\
(.31)\end{array}$ & $\begin{array}{c}6.0 \\
(.00)\end{array}$ & $\begin{array}{c}5.9 \\
(.45)\end{array}$ & $\begin{array}{c}5.6 \\
(1.06)\end{array}$ & $\begin{array}{c}5.9 \\
(.22)\end{array}$ & $\begin{array}{c}5.9 \\
(.20)\end{array}$ & $\begin{array}{c}5.8 \\
(.52)\end{array}$ & $\begin{array}{c}3.7 \\
(1.17)\end{array}$ & $\begin{array}{c}3.6 \\
(.99)\end{array}$ & $\begin{array}{c}4.0 \\
(.41)\end{array}$ & $\begin{array}{c}3.5 \\
(.76)\end{array}$ & $\begin{array}{c}3.1 \\
(1.34)\end{array}$ & $\begin{array}{c}2.6 \\
(.96)\end{array}$ & $\begin{array}{c}3.6 \\
(1.23)\end{array}$ & $\begin{array}{c}2.9 \\
(1.05)\end{array}$ & $\begin{array}{c}A, B C, A D \\
C D\end{array}$ \\
\hline Generalizability & $\begin{array}{c}5.7 \\
(.94)\end{array}$ & $\begin{array}{c}5.9 \\
(.22)\end{array}$ & $\begin{array}{c}5.8 \\
(.80)\end{array}$ & $\begin{array}{c}5.9 \\
(.45)\end{array}$ & $\begin{array}{c}5.4 \\
(1.28)\end{array}$ & $\begin{array}{c}5.8 \\
(.62)\end{array}$ & $\begin{array}{c}5.9 \\
(.28)\end{array}$ & $\begin{array}{c}5.7 \\
(.75)\end{array}$ & $\begin{array}{c}4.1 \\
(.99)\end{array}$ & $\begin{array}{c}3.8 \\
(.93)\end{array}$ & $\begin{array}{c}3.9 \\
(.64)\end{array}$ & $\begin{array}{c}4.0 \\
(.89)\end{array}$ & $\begin{array}{c}3.5 \\
(1.57)\end{array}$ & $\begin{array}{c}3.0 \\
(1.41)\end{array}$ & $\begin{array}{c}3.5 \\
(1.05)\end{array}$ & $\begin{array}{c}3.8 \\
(1.21)\end{array}$ & $A, B C D$ \\
\hline $\begin{array}{l}\text { YL = young left- } b \\
\text { OL = old left-beh } \\
A=\text { main effect } f \\
C=\text { main effect } \mathrm{f}\end{array}$ & $\begin{array}{l}\text { ehind ch } \\
\text { ad childr } \\
\text { r domai } \\
\text { r sex }\end{array}$ & Idren & & & & & & $\begin{array}{l}\text { ON } \\
\text { B } \\
D\end{array}$ & $\begin{aligned} & =\text { young } \\
I= & \text { old nc } \\
= & \text { main ef } \\
= & \text { main e }\end{aligned}$ & $\begin{array}{l}\text { non-left } \\
\text { n-left-be } \\
\text { fect for } \\
\text { fect for }\end{array}$ & $\begin{array}{l}\text { behind } \\
\text { ind ch } \\
\text { ge } \\
\text { hildren }\end{array}$ & $\begin{array}{l}\text { childre } \\
\text { ldren } \\
\text { status }\end{array}$ & & & & & \\
\hline
\end{tabular}

Table 2. Mean (and SD) Criterion Judgment Scores for Each Social Domain by Status and Age 
the participants reported that it was more acceptable to commit a personal transgression than to violate a conventional rule, $p<.01, M D=-1.84$. In turn, it was more acceptable to commit a conventional infraction than to commit either a moral physical infraction, $p<.01, M D=-.15$, or a moral psychological infraction, $p<.05, M D=-.15$. The acceptability scores for moral physical and moral psychological infractions did not differ from one another.

The mixed design ANOVA results indicated that there were no main effects in age, gender, and status in participants' judgments about infractions in social domains. However, there was interaction between age and gender, $F(1.3$, 102.8)=4.06, $p<.05, \quad \eta_{p}{ }^{2}=.05$. A one-way ANOVA showed that this interaction mainly represented in the evaluation of personal rules and violations, $F(3,83)=3.14, p<.05$. Post-hoc results further indicated: males and females in the younger age group differed in their evaluation of acceptability of personal transgressions, $p<.01, M D=-1.10$, which indicated that younger males were more ready than younger females to accept personal transgressions; Meanwhile, both males and females in the two age groups differed in their judgment of personal transgressions, but in the opposite directions, $p<.05, M D=-.82, p<.05, M D=.81$, respectively, which indicated that males' acceptability to personal transgressions decreased with age, while females' acceptability grew with age.

Significant difference was found in legitimacy of rule-making by authority in conventional domain among the two age groups, $F$ (1, $85)=5.37, \quad p<.05, \eta_{p}^{2}=.06$. This indicated that younger children were more ready than older ones to accept the rules made by parents or teachers in the conventional domain.

In summary, all participants reported that it was legitimate for parents and teachers to establish rules concerning the moral and conventional domains but not for the personal domain.

Alterability. The $4 \times 2 \times 2 \times 2$ mixed ANOVA applied to the participants' scores for the acceptability of authority to negate rules with regard to each of the acts in each domain revealed significant effect for domain, $F$ (2.1, 154.7)=227.18, $p<.001, \eta_{p}{ }^{2}=.79$. As the means in Table 1 showed, the participants indicated via pairwise comparison that, in comparison to the rules within the conventional domain, it was more acceptable for authority to get rid of the rules within the personal domain, $p<.01, M D=-.75$. In comparison to getting rid of the conventional rules, participants reported that it was not acceptable to modify the rules pertaining to either the moral physical domain, $p<.001, M D=-2.17$, or the moral psychological domain, $p<.001, M D=-1.98$. The participants differed in moral physical and moral psychological rules on alterability, $p<.05, M D=.19$. Thus, it was acceptable for parents and teachers to change personal rules in comparison to conventional rules. Furthermore, the children considered it acceptable for parents and teachers to get rid of the 
conventional rules in comparison to moral psychological rules, and moral physical rules were considered absolute.

Males and females differed in the alterability of rules concerning moral psychological issues, $F(1,85)=5.53, p<.05, \eta_{p}{ }^{2}=.06$, which indicated it was more difficult for females to accept the change or abolishment of such rules. However, there was interaction between social domains and age groups, $F$ (2.1, $154.7)=3.7, p<.05, \eta_{P}^{2}=.05$. In particular, the younger participants differentiated moral physical and moral psychological rules concerning rule alterability, $p<.05$, $M D=.31$, and perceived conventional and personal rules differently, $p<.01, M D$ $=1.13$. However, the older participants didn't differentiate both pairs of rules.

Rule contingency. The $4 \times 2 \times 2 \times 2$ mixed ANOVA indicated a main effect for domain, $F(2.4,182.8)=337.20, p<.01, \eta_{p}^{2}=.81$. This effect, showed by pairwise comparison, was due to participants' reports that moral physical and moral psychological transgressions would be considered wrong or unacceptable even if there were no rules regulating such behaviours. However, conventional infractions would be acceptable if there were no explicit conventional rules, in contrast to moral physical and moral psychological rules, $p<.01, M D=-2.27$, $p<.01, M D=-2.12$, respectively. Furthermore, such conventional behaviours would be considered more unacceptable than behaviours in the personal domain if such behaviours were not prohibited by rules, $p<.01, M D=.63$. Thus, participants considered moral infractions unacceptable regardless of whether there was a rule, less so for conventional behaviours, and acceptable for personal behaviours if a specific rule was negated.

Interaction existed between social domains and children's status (LB or NL), $F(2.4,182.8)=4.12, p<.05, \quad \eta_{p}^{2}=.05$. One-way ANOVA results revealed that LBs and NLs differed in rule contingency of personal infractions, $F(1,84)=5.06$, $p<.05, M D=.57$, which indicated that LBs considered it unacceptable to commit a personal infraction even there was no rule banning it, while NLs considered it acceptable.

Interaction also existed between gender and age group, $F(1,77)=4.25$, $p<.05, \eta_{P}{ }^{2}=.05$. In particular, the younger males and females differed between moral psychological rules on contingency, $F(1,81)=4.0, p<.05, M D=-.72$, which indicates that the younger males thought it was acceptable to commit a psychological infraction if there was no rule prohibiting it while the younger females believed it was wrong to do so. Significant difference existed in personal rules on contingency among male participants of the two age groups, $F$ $(1,81)=7.03, p<.01, M D=-.99$, which indicated that the younger males believed it was all right, compared with the older males, to commit a personal infraction if there was no explicit rule banning it. Further analysis revealed that it was the vignette concerning hair style that made the difference, $F(1,40)=11.95, p<.001$.

Generalizability. In assessing whether the participants believed it would be unacceptable not to have a rule regulating these behaviors across different contexts, the mixed ANOVA revealed a main effect for domain, $F(2.2$, 
168.8)=167.9, $p<.01, \eta_{p}{ }^{2}=.69$. All participants believed there was a significant difference between conventional rules and moral physical or moral psychological rules, $p<.01, M D=-1.87, p<.01, M D=-1.70$, respectively, while they didn't differentiate between moral physical and moral psychological rules. Additionally, the participants responded that the personal rules were not generalizable across settings, in contrast to the conventional rules, $p<.01, M D=-$ .56. Therefore it was acceptable to have no specific personal rules across different contexts.

The younger male LBs held a very unique attitude towards generalizability of moral psychological rules. Generally speaking, they were more willing to accept situations having no moral psychological rules compared with younger female LBs $(p<.01, M D=-1.25)$, older male LBs $(p<.01$, $M D=-1.33)$, and younger male NLs ( $p<.01, M D=-1.11)$.

Finally, there was significant difference in the generalizability of moral physical rules between the male and female LBs, $p<.05, \quad M D=-.46$. This showed that the LB males were more unwilling, compared with LB females to accept the generalizability of moral physical rules. In other words, they viewed moral physical infractions acceptable in certain contexts.

\subsection{Justifications}

Participants were also asked to justify their reasoning and judgments. The percentage of the justification categories is presented in Table 3.

Social domain

\begin{tabular}{|c|c|c|c|c|c|}
\hline \multicolumn{2}{|c|}{ Justification category } & \multicolumn{2}{|c|}{ Moral } & \multirow[b]{2}{*}{ Conventional } & \multirow[b]{2}{*}{ Personal } \\
\hline & $\begin{array}{l}\text { Child } \\
\text { status }\end{array}$ & Physical & Psychological & & \\
\hline \multirow[t]{2}{*}{ Moral } & LB & 91 & 88 & 0 & 1 \\
\hline & NL & 86 & 84 & 2 & 0 \\
\hline \multirow[t]{2}{*}{ Conventional } & LB & 23 & 8 & 95 & 73 \\
\hline & NL & 16 & 4 & 100 & 41 \\
\hline \multirow[t]{2}{*}{ Punishment } & LB & 18 & 5 & 4 & 6 \\
\hline & NL & 16 & 8 & 2 & 0 \\
\hline \multirow[t]{2}{*}{ Retaliation } & LB & 10 & 31 & 0 & 0 \\
\hline & NL & 10 & 18 & 0 & 0 \\
\hline \multirow{2}{*}{$\begin{array}{l}\text { Personal } \\
\text { growth }\end{array}$} & LB & 18 & 16 & 1 & 0 \\
\hline & NL & 35 & 37 & 3 & 4 \\
\hline \multirow{4}{*}{$\begin{array}{l}\text { Personal } \\
\text { choice } \\
\text { Relationship }\end{array}$} & LB & 0 & 2 & 4 & 67 \\
\hline & NL & 0 & 0 & 2 & 63 \\
\hline & LB & 4 & 9 & 0 & 0 \\
\hline & NL & 4 & 12 & 0 & 0 \\
\hline
\end{tabular}

Table 3. Percentage of Children Using Justification Category by Social Domain

Moral justifications. As indicated in Table 3, both left- and non-leftbehind children mainly used moral justifications in moral physical and moral psychological domains, with the former a little higher (90\% VS 85\%). 
Participants seldom used moral justifications in conventional and personal domains, so no further analysis was conducted on these data.

Conventional justifications. Contrasted with the dominant use of moral justifications in the moral domain, conventional justifications were widely used by both LBs and NLs in all domains, although mainly in conventional and personal domains. However, there were some differences between the two groups: 1 . LBs used more conventional justifications than NLs, especially in the personal domain (73\% VS 41\%); 2 . the younger LBs used more conventional justifications than older LBs in the personal domain $(86 \%$ VS $60 \%$ ), while there was no big gap between the two age groups for NLs (73\% VS 68\%).

Punishment justifications. Punishment justifications were also used in all domains, but mainly in moral domains, the same as LBs and NLs (18\% VS $16 \%)$. Furthermore, the younger age group used punishment justifications more frequently than the older group, the same as LBs and NLs, $15 \%$ VS $8 \%$, $17 \%$ VS $8 \%$ respectively.

Retaliation justifications. The legitimacy of rule-making by authority. The $4 \times 2 \times 2 \times 2$ mixed ANOVA on responses regarding the acceptability of parents or teachers making rules about acts in each of the four domains showed a significant effect for domain, $F(1.9,152.4)=57.2, \quad p<.01$, $\eta_{p}{ }^{2}=.42$. As the means in Table 1 illustrated, pairwise comparison revealed that both LBs and NLs reported that it was less acceptable for parents or teachers to make rules regarding behaviours in the personal domain than in the conventional domain, $p<.01, M D=1.11$, and they felt it was less acceptable for authority to make rules regarding acts in the conventional domain than in either the moral physical, $p<.01, M D=.34$ or moral psychological domains, $p<.01, M D=.43$.

All participants solely used retaliation justifications in the moral domain, especially in the moral psychological domain. LBs used more retaliation justifications than NLs (31\% VS 18\%). Furthermore, the retaliation justifications used by younger LBs were higher than that of the older LBs (25 \% VS 13\%), especially in the moral psychological domain (37\% VS 13\%). Although there was no significant difference between the two age groups of NLs, the younger ones used fewer retaliation justifications (15\% VS 20\%)

Personal growth justifications. This kind of justification was also widely used in all domains, mainly in the moral domain. LBs used fewer personal growth justifications than NLs (17\% VS 36\%), and the younger LBs used growth justifications more frequently than older counter parts $(25 \%$ VS $11 \%)$. There was no such difference between the two age groups of NLs (37\% VS 36\%).

Personal choice justifications. Personal-choice justifications were used in conventional and personal domains, especially the personal domain. 
There was no significant difference between LBs and NLs (67\% VS 63\%); neither was there age difference.

Interpersonal relationship justifications. This kind of justifications was only used in the moral domain. Younger participants used it more frequently than older ones (15\% VS 8\%).

\section{Discussion}

\subsection{Criterion judgment}

The purpose of this study was to explore, based on social cognitive domain theory, whether there are some differences in the reasoning for social and authoritative rules between left-behind and non-left-behind children in rural China. In general, the difference between LBs and NLs was not as big as we supposed, which proves that the image of left-behind children in social media is somewhat distorted or overgeneralized. Both groups in this study responded in a manner that is consistent with previous research findings pertaining to the criterion judgment responses. For example, moral infractions were judged to be most unacceptable, followed by conventional infractions, and personal infractions were judged to be the most acceptable (cf. Smetana 2006; Turiel 2006).

However, responses to the act-evaluation question did reveal some important differences. With increased age, both males and females had different evaluations of personal infractions. Older females considered it more acceptable to commit personal infractions, which coincided with previous studies that with age, particularly in adolescence, children claim a larger share of actions as their personal right and beyond parental control (Smetana 1988; Tisak \& Tisak 1990). The most surprising finding was that, compared with older males, younger males believed it more acceptable to commit a personal infraction. Meanwhile, younger males considered it alright to commit a personal infraction if there is no explicit rule about it. What can be concluded here is that males' personal boundaries shrink with age. Further analysis revealed that it was mainly the vignette concerning hair style made the difference, $F(1,40)=5.13, p<.05$. The possible reason was that older males were often instructed not to have long hair, which is a common practice in local middle school. Because some of them may show personal expressions in such a way, so the older males regarded such issues as conventional more than personal and considered them dependent on rules. Or in Smetana's term, the hair style issue has turned into "contextual convention" (Smetana 1996).

The left behinds considered it unacceptable to commit a personal infraction even if there was no rule explicitly banning it while non-left behinds put personal issues under their own jurisdiction, refusing to be supervised by rules and authorities. This echoed other research. For example, Nucci (1982) found that behaviour-disordered children were less likely than normal to 
identify acts as within their personal domain. This suggested that left behinds were less certain about the boundary of self and the realm of authority, so it is very difficult for them to identify personal responsibility and autonomy. As Nucci suggested, intervention procedures needed to address the development of a sense of personal autonomy as part of an approach designed to foster the social growth of left-behind children.

Furthermore, younger participants were more ready to accept the rules made by authorities. However, the younger group, compared with the older group, considered change in moral physical rules less acceptable than that of moral psychological rules. This may be related to children's cognition: Physical harm is more direct, obvious, and easier for younger children to perceive, and they only could have a better understanding of psychological harm with age. That is to say, children's understanding and perceptions of psychological harm grew with age, which led them to consider moral physical rules and moral psychological rules to have the same importance; they should not be changed or abolished. Additionally, the younger participants differentiated conventional and personal rules, but older participants did not. The possible reason was that children realized the relativity and alterability of conventional rules with age and would tend to consider both conventional and personal rules as changeable. This correlates with Turiel's description of children's and adolescents' development of concepts of convention. In Turiel's opinion (1983), teenagers at 12 to 13 years of age are at the negation stage of convention in which convention is seen as arbitrary and changeable regardless of rules. Conventions are "nothing but" social expectations. However, teenagers at ten to 11 years of age hold a positive attitude towards conventions and tend to adhere to them based on concrete rules and authoritative expectations.

Finally, some gender differences were found in this study. First, personal infractions were more acceptable for younger males than for younger females. This may have something to do with different Chinese concepts of cultivation of boys and girls. Generally speaking, Chinese parents expect girls to be more obedient and to conform to social norms, thus they exert stricter discipline on girls' infractions. As for boys, the story is a little different. Chinese parents are more tolerant of boys' personal or conventional infractions and even regard them as signals of brightness and cleverness. Second, male participants were more ready to accept changing or abolishing psychological rules than females. In other words, females considered psychological rules to be more absolute and unchangeable than males did. The possible reason is that females are more sensitive to psychological harm, thus they hold a stronger objection to changing or abolishing psychological rules.

\subsection{Justifications for judgments about rules}

As expected, moral justifications were mainly used in the moral domain (both moral physical and psychological). In contrast, conventional justifications were 
widely used in all domains, the same for LBs and NLs. However, LBs more frequently used conventional justifications in moral and personal domains than NLs. These findings are consistent with those reported by Nucci \& Herman (1982), Tisak, M. S., \& Jankowski, A. (1996) and Mullins \& Tisak (2006) in that the behaviorally disordered children, adolescent offenders, or foster youth referred to authority issues in response to personal rules. Furthermore, the younger LBs used more conventional justifications for personal infractions than NLs, which indicates that LBs had less autonomy and independence. The possible explanation is that LBs were mainly brought up by grandparents who generally pamper children and are willing to do everything for them and expect them to be obedient. Thus the LBs maybe were accustomed to follow others' directions and had less awareness of self-reliance and self-decision.

Furthermore, the younger participants used punishment justifications more frequently than older participants, which indicated that younger children more often justified their actions on external norms-i.e., actions were wrong when they would be punished and right when they would not be punished. They gradually turned from these external justifications to intrinsic consequences. When they justified an action, they would use fewer punishment justifications. Retaliation justifications were solely used in the moral domain, which indicated that they consider moral infractions the most serious ones and deserved retaliation. Retaliation justifications were used more frequently by LBs than by NLs, especially for moral psychological infractions. The possible reason was that LBs may experience more physical and psychological harm, and the negative emotions accompanying the harm thus generated a stronger desire to push back. On the other hand, they tended to seek revenge when psychologically harmed, possibly because they were psychologically fragile due to the absence of parents. The younger and more fragile they were, the younger LBs used retaliation justifications, much more than other groups. This was proved from the aspect that NLs expressed no such difference between the younger and older groups

\subsection{Limitations and Conclusions}

This study tries to explore the development of moral reasoning in left behind children by using first-hand data. However, due to limited time and energy, the future research can improve on this in several aspects. First, samples can be more various and larger. All participants in the current study came from the same town, and their parents have been away from home for more than five years. Actually, left behinds in different areas may have different stories, and there are lots of subtypes of left-behind children: greater variations in left-behind time, variability in the status of being left behind ( both parents away from home; only one parent being away; living with grandparents, other relatives, or alone). Future studies may include more types of participants to get 
a more comprehensive picture of this population. Second, little attention was paid to the family background of NLs. Some parents, even though at home, may contribute little to children's development. That is, some children may be "virtual" left-behind children" (being ignored by parents) even though they live with their parents. The results in the current study revealed that there were no significant differences in most aspects of moral reasoning and justification between LBs and NLs. The possible interpretation is that left-behinds are not so bad, but it could also be the case that the NLs are not so good. In other words, some parents may fail to facilitate children's social development effectively even when they live with their children. This is enlightening for the moral education of all children.

\section{References}

All China Women's Federation Research Group. 2013. "Research Report Into the Situation of Rural Left Behind Children and Rural to Urban Migrant Children." China Women's Movement, Vol. 6: 30-34.

Du Huanhuan. 2012. "The Difference in the Moral Development of Stay-atHome Children in Rural Areas: With Foshan as an Example." Academic Exploration, Vol. 7: 80-83.

Mullins, D. \& M. S. Tisak. 2006. "Moral, Conventional, and Personal Rules: The Perspective of Foster Youth." Journal of Applied Developmental Psychology, Vol. 27(4): 310-325.

Killen, M., N. G. Margie, S. \& Sinno. 2006. "Morality in the Context of Intergroup Relationships." In Killen, M. \& J. Smetana (eds.) Handbook of Moral Development (pp. 155-183). Hillsdale, NJ: Lawrence Erlbaum.

Ming, W., S.. Su, X. Li, \& D. Lin. 2014. "Positive Youth Development in Rural China: The Role of Parental Migration." Social Science \& Medicine, Vol. 132(1982): 261-269.

Mullins, D. \& M. S. Tisak. 2006. "Moral, Conventional, and Personal Rules: The Perspective of Foster Youth." Journal of Applied Developmental Psychology, Vol. 27(4): 310-325.

Nucci, L. P. 1981. "The Development of Personal Concepts: A Domain Distinct from Moral or Societal Concepts." Child Development, Vol. 52: 114-121.

Nucci, L. P. \& S. Herman. 1982. "Behavioral Disordered Children's Conceptions of Moral, Conventional, and Personal Issues." Journal of Abnormal Child Psychology, Vol. 10: 411-426.

Su, S., X. Li, D. Lin, X. Xu, \& M. Zhu. 2013. "Psychological Adjustment Among LeftBehind Children in Rural China: The Role of Parental Migration and Parent-Child Communication." Child Care Health \& Development, Vol 39(2): 162-170.

Smetana, J. G. \& J. L. Braeges. 1990. “The Development of Toddlers' Moral and Conventional Judgments." Merrill-Palmer Quarterly, Vol 36(3): 329-346. 
Smetana, J. G. 1988. "Adolescents' and Parents' Conceptions of Parental Authority." Child Development, Vol. 59: 321-335.

Smetana, J. G. 2006. "Social-Cognitive Domain Theory: Consistencies and Variations in Children's Moral and Social Judgments." In Killen M. \& J. Smetana (eds.) Handbook of Moral Development (pp. 119-153). Hillsdale, NJ: Lawrence Erlbaum.

Smetana, J. G., M. Kelly, \& C. T. Twentyman. 1984. "Abused, Neglected, and Nonmaltreated Children's Conceptions of Moral and SocialConventional Transgressions." Child Development, Vol. 55: 277-287.

Smetana, J. G., B. Bitz. 1996. "Adolescents' Conceptions of Teachers' Authority and Their Relations to Rule Violations in School." Child Development, Vol 67(3):1153-1172.

Tisak, M. S., J. Tisak, S. E. \& Goldstein. 2006. "Aggression, Delinquency, and Morality: A Social-Cognitive Perspective." In Killen, M. \& J. Smetana (eds.) Handbook of Moral Development (pp. 611-629). Hillsdale, NJ: Lawrence Erlbaum.

Tisak, M. S. \& E. Turiel. 1984. "Children's Conceptions of Moral and Prudential Rules." Child Development, Vol 55: 1030-1039.

Tisak, M. S. 1986. "Children's Conceptions of Parental Authority." Child Development, Vol. 57: 166-176.

Tisak, M. S. \& A. Jankowski. 1996. "Societal Rule Evaluations: Adolescent Offenders' Reasoning About Moral, Conventional and Personal Rules." Aggressive Behavior, Vol. 22: 195-207.

Tisak, M. \& J. Tisak. 1990. "Children's Conceptions of Parental Authority, Friendship, and Sibling Relations." Merrill-Palmer Quarterly, Vol. 36: 347-367.

Turiel, E. 1983. The Development of Social Knowledge: Morality and Convention. Cambridge: Cambridge University Press.

Turiel, E. 2002. The Culture of Morality: Social Development, Context, and Conflict. Cambridge: Cambridge University Press.

Turiel, E. 2006. "Thought, Emotions, and Social Interactional Processes in Moral Development." In Killen, M. \& J. Smetana (eds.) Handbook of Moral Development (pp. 7-35). Hillsdale, NJ: Lawrence Erlbaum.

Wang, L. \& M. Li. 2014. "The Situation and Reflection on Moral Education of Left-Behind Children in Rural Area." Educational Research and Experiment, Vol. 6: 41-44.

Wen, M. \& D. Lin. 2012. "Child Development in Rural China: Children Left Behind by Their Migrant Parents and Children of Nonmigrant Families." Child Development, Vol. 83(1): 120-136.

Zhang, W. W. 2004. Transforming China: Economic reform and its political implications. New York: St. Martin's Press. 
Jianjin Liu

(Guangdong University of Foreign Studies, liujianjinljj@126.com)

\title{
Social Cognitive Domain Coordination in Left-Behind Children: A Comparative Study of Left-Behind and Non-Left-Behind Children in Rural China
}

\begin{abstract}
Forty-seven left-behind children (LB) and 40 non-left-behind children (NL) in rural China were interviewed to evaluate moral, conventional, and personal violations by providing judgments and justifications. The results suggested that both LBs and NLs differentiate the rules of moral, conventional and personal domains. However, there are some differences: 1 . The NL considered it acceptable to commit a personal infraction when there was no rue prohibiting it, while the LB considered it wrong; 2. The younger male LBs were more willing to accept situations without moral psychological rules, compared with younger female LBs, older male LBs, and younger male NLs. Age, sex differences were also found. The one out of our expectation is that younger males considered it more acceptable to commit a personal infraction than older males did and believed it all right if there was no explicit rule on it. Meanwhile, in providing reasons to support their judgments or evaluations, the findings revealed that: 1 . More often LBs referred to social conventional reasoning even when evaluating moral and personal rules and violations, especially on personal issues; 2. LBs used more justifications of punishment and fewer justifications of personal growth. The implications of the results of the study for children's moral development and education, especially for LBs, are discussed.
\end{abstract}

Key words: left-behind children; non-left-behind children; moral domain; conventional domain; personal domain

Ethics in Progress (ISSN 2084-9257). Vol. 7 (2016). No. 1, Art. \#17, pp. 246-283.

doi: 10.14746/eip.2016.1.14 